\title{
DESAFIOS DA EDUCAÇÃO NA GARANTIA DE DIREITOS: PRO- FESSORES DO CURSO DE MAGISTÉRIO E SUA EXPERIÊNCIA COM O ESTATUTO DA CRIANÇA E DO ADOLESCENTE
}

CHALLENGES OF EDUCATION IN THE GUARANTEE OF RIGHTS: TEACHERS OF THE MAGISTERIUM COURSE AND ITS EXPERIENCE WITH THE STATUS OF CHILDREN AND ADOLESCENTS

\section{Marina de Mello Borsatto', João Henrique Zanelatto ${ }^{2}$}

RECEBIDO EM: 22/05/2017 / APROVADO EM: 23/07/2017

DOI: $10.5902 / 2317175825841$

\section{RESUMO}

A educação constitui-se em um dos caminhos que pode auxiliar na mudança de vida do ser humano, porém, quando não possui qualidade, acaba se tornando um fardo. O desempenho dos/as alunos/as se torna melhor quando os profissionais da educação são bem qualificados e estão preparados para agir não apenas dentro da sua área de atuação, mas também na garantia dos direitos de todos os cidadãos e cidadãs, principalmente os/as que se encontram em situação de vulnerabilidade. O objetivo deste estudo foi analisar se os/as profissionais da educação estão preparados/as para agir na garantia dos direitos das crianças e dos/as adolescentes, com base no Estatuto da Criança e do Adolescente. Mediante a aplicação de um questionário, foi possível identificar o nível de conhecimento dos/as professores/as que lecionam no curso de magistério da Escola Sebastião Toledo dos Santos, situada em Criciúma, SC. Verificou-se que, apesar dos obstáculos que a educação enfrenta, os/as professores/as conhecem as leis que garantem os direitos deste público e interferem sempre que necessário.

Palavras-chave: Educação, Direitos, Criança, Adolescente.

\footnotetext{
1 Graduada em Ciências Biológicas e especialista em Educação, Diversidade e Redes de Protação Social. E-mail: marina_borsatto@hotmail.com.

2 Doutor e Doutor em História, professor do Curso de Economia, História e do Programa de Pós-Graduação em Desenvolvimento Socioeconômico da Universidade do Extremo Sul Catarinense. Pesquisador do Núcleo de Estudos em Estado, Política e Direito (NUPED/UNESC) e membro do grupo de pesquisa "História Econômica e Social de Santa Catarina". E-mail: jhz@unesc.net.
} 
DESAFIOS DA EDUCAÇÃO NA GARANTIA DE DIREITOS:

PROFESSORES DO CURSO DE MAGISTÉRIO E SUA EXPERIÊNCIA COM O ESTATUTO DA CRIANÇA E DO ADOLESCENTE

\begin{abstract}
Education is one of the ways that can help change the life of a human being, but when it does not have quality, it becomes a burden. The performance of students becomes better when education professionals are well qualified and prepared to act not only within their area of practice, but also to guarantee the rights of all citizens, especially those who are vulnerable. The objective of this study was to analyze whether education professionals are prepared to act to guarantee the rights of children and adolescents based on the Statute of the Child and Adolescent. Through the application of a questionnaire, it was possible to identify the level of knowledge of the teachers who teach in the teaching course of the Sebastião Toledo dos Santos School, situated in Criciuma, SC. It has been found that despite the obstacles that education faces, teachers know the laws that guarantee the rights of this public and interfere whenever necessary.
\end{abstract}

Keywords: Education, Rights, Child, Adolescent.

\title{
1 Introdução
}

\begin{abstract}
É dever da família, da sociedade e do Estado assegurar à criança e ao adolescente, com prioridade absoluta, o direito à vida, à saúde, à alimentação, à educação, ao lazer, à profissionalização, à cultura, à dignidade, ao respeito, à liberdade e à convivência familiar e comunitária, além de colocá-los à salvo de toda forma de negligência, discriminação, exploração, violência, crueldade e opressão. (Constituição Federal, 1988).
\end{abstract}

O atual cenário da política em nosso País, juntamente com o aumento constante da criminalidade, faz-nos refletir sobre o andamento do processo de ensino-aprendizagem nas escolas. Acredita-se que a educação pode mudar o mundo, porém, quando nos deparamos com índices assustadores de evasão escolar e um índice alarmante de jovens envolvidos/as com o tráfico e uso de drogas, questionamo-nos se a educação tem cumprido seu papel na sociedade, se os/as professores/as e profissionais da educação têm ciência do índice de abandono escolar e se, de fato, conhecem a realidade dos/as seus/suas alunos/as.

O objetivo da pesquisa foi identificar o nível de conhecimento dos/as professores/as que lecionam no curso de magistério da Escola Sebastião Toledo dos Santos, situada em Criciúma/SC, no que tange à garantia dos direitos das crianças e dos/as adolescentes/as, estabelecidos pelo ECA ${ }^{1}$. A pesquisa foi realizada mediante a aplicação de um questionário disponibilizado aleatoriamente a dez professores/as. A Escola Sebastião Toledo dos Santos situa-se no centro de Criciúma e é a maior escola estadual da cidade. A instituição possui turmas de ensino médio e de magistério nos períodos matutino, vespertino e noturno, e também recebe alunos e alunas dos vários bairros da cidade e de 1 A criação do Estatuto da Criança e do Adolescente - ECA teve início em 1989, a partir do movimento realizado por vários integrantes da sociedade civil, ministério público, judiciário e órgãos governamentais de várias regiões do País. Foi dessa mobilização que, no ano seguinte - 13 de julho de 1990 -, foi aprovada a Lei 8.069/90, que cria o ECA. O Estatuto da Criança e do Adolescente foi estruturado em dois livros: o Livro I trata dos direitos sociais e é destinado a todas as crianças e adolescentes; o Livro II trata da política de atendimento e é destinado a crianças e adolescentes em situação de risco pessoal e social, tanto pela sua conduta quanto em razão da ação ou omissão dos responsáveis - pais, sociedade e Estado (ECA, 2012). 
outros municípios. Ela foi escolhida para a realização da pesquisa por ser uma das poucas escolas situadas na região que ainda forma professores/as em nível de ensino médio para atuar nas séries iniciais.

Acredita-se que o/a professor/a que forma futuros/as professores/as deva ser o/a principal agente incentivador/a na garantia dos direitos das crianças e dos/as adolescentes. Por estar constantemente nas salas de aula lidando com este público, necessita ter domínio básico das leis para saber quando aplicá-las e assim não se tornar um/a omissor/a de garantias e direitos de um outro cidadão.

O período da infância e da adolescência é a fase principal da vida de um cidadão, na qual são construídos seus valores, seu caráter e sua personalidade. Sem dúvida alguma, profissionais mais bem qualificados podem influenciar positivamente na vida de estudantes que estejam sobre risco de perda de garantias e direitos já adquiridos. Espera-se que todo/a profissional possa estar preparado/a para agir, sempre que necessário, na garantia dos seus direitos e dos do próximo, visando sempre à construção de uma sociedade mais justa.

No que tange à metodologia, foi realizada uma pesquisa mediante a aplicação de um questionário respondido aleatoriamente por dez professores/ as que lecionam no curso de magistério da Escola Sebastião Toledo dos Santos, em Criciúma, para verificar o conhecimento destes/as quanto ao Estatuto da Criança e do Adolescente - ECA, sobretudo quanto aos direitos estabelecidos por ele, relativos ao papel da Comunidade Escolar na inserção, proteção e defesa dos/as educandos/as. Por meio da catalogação e da análise dos dados coletados no questionário, foi possível identificar o nível de conhecimento dos/ as professores/as em relação ao Estatuto da Criança e do Adolescente - ECA.

\section{Fases de acompanhamento e apoio}

A infância e a adolescência são dois períodos da vida considerados pelos/ as adultos/as como a melhor fase. Muitos, certamente, já pensaram ou disseram que, se pudessem, gostariam de voltar a ser criança. Apesar de a criança existir desde os primórdios da humanidade, o conceito referente a essa fase da vida, bem como os seus sentimentos, só começou a ser estudado a partir do século XIII. É possível observarmos tal afirmação em Carvalho:

[...] A aparição da infância ocorreu em torno do século XIII e XIV, mas os sinais de sua evolução tornaram-se claros e evidentes, no continente europeu, entre os séculos XVI e XVIII, no momento em que a estrutura social vigente (Mercantilismo) provocou uma alteração nos sentimentos e nas relações frente à infância. (CARVALHO, 2003, p. 47).

Atualmente, muitas pessoas ainda confundem a definição dos períodos entre a infância e a adolescência. Nesse sentido, para demarcarmos estes dois 
DESAFIOS DA EDUCAÇÃO NA GARANTIA DE DIREITOS:

períodos, usamos como base a seguinte definição (Lei $n^{\circ} 8.069 / 90$, art. $2^{\circ}$ ) do Estatuto da Criança e do Adolescente: "Considera-se criança, para os efeitos desta Lei, a pessoa até doze anos de idade incompletos, e adolescente aquela entre doze e dezoito anos de idade." (BRASIL, 1990). Partindo da legislação estabelecida pelo ECA, podemos nos aprofundar ainda mais e dividir o período da infância até a adolescência em vários períodos, de acordo com as definições acordadas entre psicólogos, médicos pediatras e psicopedagogos:

0-18 meses: Fase em que o bebê é completamente dependente de terceiros (geralmente dos pais) para alimentação, higiene e locomoção. Esse período é caracterizado pelo egocentrismo. Nele, o bebê age por instinto, como se o mundo girasse ao seu redor, e ainda não se vê como parte de uma sociedade.

18-3 anos: A pequena criança começa a desenvolver habilidades nessa fase da vida, como falar e andar, e a se tornar um pouco independente. A grande maioria começa a aprender algumas palavras e, ao longo desse período, vai aperfeiçoando seu vocabulário.

3-4 anos: A criança desenvolve aspectos básicos de independência e começa a se tornar menos egocêntrica, pois começa a perceber o mundo à sua volta. Esse período também é conhecido como fase de identificação, pois a criança desenvolve padrões de comportamento com base nos laços de amizade e nas semelhanças físicas ou psicológicas.

5-9 anos: A grande maioria das crianças, nessa faixa de idade, já tem padrões de comportamento bem definidos. É nessa fase que o psicológico e o emocional são marcados pelo seu grande desenvolvimento.

10-12 anos: Ocorrem várias mudanças físicas; a criança passa a ter mais responsabilidade e a dar mais importância aos grupos que têm gostos semeIhantes aos seus. Nessa fase, também começam as preocupações com a aceitação nos grupos, e a criança, muitas vezes, acaba se desvinculando do modelo proposto pelos pais, pois, às vezes, não se identifica com esse modelo.

Podemos observar que o período da infância é dividido em faixas de idades e que em cada uma delas ocorre uma transformação diferente. É importante e válido ressaltar que quanto mais estímulo a criança recebe, mais ela consegue desenvolver tais habilidades.

O período da adolescência também é marcado por grandes mudanças, tanto físicas como psicológicas. É o período de preparação para a fase adulta. Existe uma perspectiva tradicional dos estudos, a qual indica que a fase da adolescência é turbulenta e, muitas vezes, conturbada. A grande quantidade de transformações pode causar uma crise de identidade nos/as adolescentes. Há uma confusão de papéis e uma dificuldade de estabelecer a própria identidade. Matheus (2008, p. 28) afirma que isso:

[...] circunscreve a um momento específico da vida, com um fim previamente estabelecido, turbulências inevitáveis que cada sujeito é convocado a experimentar, a fim de conquistar a condição de indivíduo, seguindo as diretrizes do ideário da moder- 
nidade. A crise é, então, fruto do exercício da interioridade de cada um, em função das tensões e conflitos que a configuram como tal. É o preço a ser pago pela pretensa condição de independência frente às amarras da organização social; é expressão do desamparo que sua condição (imaginária) de autonomia exige, servindo, ao sujeito, como provação anônima para alcançar o estatuto de indivíduo.

De acordo com o meio onde esse/a adolescente vive e é cobrado/a ou estimulado/a, o período da adolescência pode ocorrer até atrasado - devido à infantilização - ou acelerado - devido à grande quantidade de cobrança de maturidade, responsabilidade e habilidades que ainda não competem ao indivíduo nessa fase. A passagem da adolescência para a vida adulta pode ser vista, segundo Becker (1989, p. 10), como "[...] a passagem de uma atitude de simples espectador para uma outra ativa, questionadora. Que inclusive vai gerar revisão, autocrítica, transformação".

Diferente do período da infância, a adolescência não é dividida em faixas de idade. Como já citado, tomamos como base a definição do Estatuto da Criança e do Adolescente, que define esse período dos 12 aos 18 anos. Apenas as mudanças físicas podem ser definidas de acordo com a faixa de idade; as mudanças psicológicas, cognitivas ou emocionais dependem muito do meio onde o adolescente está inserido.

A sociedade sempre buscou criar modelos e rotular exemplos como certos ou errados. Essa caracterização se dá de acordo com a religião, a cultura, o ambiente e a época, por isso é tão difícil definir esses modelos, pois cada pessoa procura se enquadrar dentro daquilo com o que mais se identifica.

Dentro das características da criança e do/a adolescente, observa-se a vulnerabilidade destes, os quais, desde o nascimento até a adolescência, precisam ter suas necessidades supridas por responsáveis adultos legais. Quando a criança ou o/a adolescente precisa trabalhar para garantir seu sustento ou o de terceiros, temos a violação de um direito desse indivíduo.

Desde que nasce, um indivíduo já tem direitos garantidos. Conforme o ECA $\left(2012\right.$, p. 9), em seu artigo $4^{\circ}$ :

É dever da família, da comunidade, da sociedade em geral e do poder público assegurar, com absoluta prioridade, a efetivação dos direitos referentes à vida, à saúde, à alimentação, à educação, ao esporte, ao lazer, à profissionalização, à cultura, à dignidade, ao respeito, à liberdade, e à convivência familiar e comunitária.

A definição de vulnerabilidade se submete à ideia de fragilidade. Nessa característica, enquadram-se as crianças e os/as adolescentes. Um fator determinante é a questão social e econômica. Quanto maior for a carência da família, maior será o risco de a criança ou o/a adolescente ter seus direitos 
DESAFIOS DA EDUCAÇÃO NA GARANTIA DE DIREITOS:

PROFESSORES DO CURSO DE MAGISTÉRIO E SUA EXPERIÊNCIA COM O ESTATUTO DA CRIANÇA E DO ADOLESCENTE

violados, visto que, em áreas socialmente vulneráveis o risco de contato com as drogas, o abandono, o abuso sexual, a prostituição ou o trabalho infantil são mais acentuados.

De forma mais ampla, a violação dos direitos das crianças e dos/as adolescentes se manifesta, na grande maioria dos casos, em seu meio familiar ou escolar. Famílias desestruturadas, sem meios de garantir a própria subsistência, acabam violando o direito dos/as menores, que por sua vez acabam indo para a escola e se deparando com profissionais muitas vezes despreparados/ as, os/as quais não conseguem identificar que esses/as menores estão sofrendo algum tipo de negligência.

Todos os anos, ingressam nas escolas inúmeras crianças e adolescentes que possuem um histórico de direitos violados. Com os índices apresentados no final dos anos, podemos observar que muitas dessas crianças e adolescentes têm um péssimo desempenho escolar, e como consequência sofrem a reprovação, por isso abandonam a escola antes mesmo de concluírem o ensino regular. A violação dos direitos, aliada a outros fatores, como a falta de preparo dos/as professores/as e demais profissionais da educação, falta de suporte psicológico e social e precarização das redes de proteção e ensino, possibilita que os índices de qualidade da educação brasileira façam com que o nosso País tenha uma baixa colocação no ranking mundial. A baixa escolaridade tem se mostrado, por meio de estudos já realizados, um dos principais indicadores entre os motivos que levam a população à pobreza extrema e à vulnerabilidade social (KASSOUF, 2007, p. 323), fazendo com que isso se torne um ciclo vicioso. Para quebrar esse ciclo, é necessário o investimento na educação de qualidade, com professores/as bem preparados para atender os/as alunos/as da meIhor forma e dar-Ihes o encaminhamento necessário para que possam manter seus direitos fundamentais garantidos e aí, então, dedicarem-se à educação, a qual tem o poder de mudar o seu futuro.

Para que os/as alunos/as tenham um bom desempenho, o/a professor/a precisa buscar criar um ambiente de aprendizagem adequado, o que nem sempre é fácil. Há, por isso, a necessidade desse/a professor/a estar bem capacitado/a para atender todo tipo de aluno/a e incluí-lo/a da melhor forma possível em suas aulas. Oliveira (2005, p. 62), citando Vygotsky, reflete sobre a intervenção pedagógica, afirmando que, na escola,

[...] o aprendizado é um resultado desejável, é o próprio objetivo do processo escolar; a intervenção é um processo pedagógico privilegiado. O professor tem o papel explícito de interferir na zona de desenvolvimento proximal dos alunos, provocando avanços que não ocorreriam espontaneamente. O único bom ensino, afirma Vygotsky, é aquele que se adianta ao desenvolvimento.

É de fundamental importância que a comunidade escolar esteja ciente do seu papel na vida de cada aluno/a. Só assim cada profissional buscará ca- 
pacitar-se ainda mais, a fim de garantir os direitos fundamentais das crianças e dos/as adolescentes e impedir que fatores contrários a isso influenciem de forma negativa no aprendizado desses/as alunos/as, que são o futuro de nosso País. Os laços formados com professores/as e colegas servirão para que a criança se sinta inserida em um grupo onde poderá aprender a reelaborar seus sentimentos de medo, de agressividade e de frustração, bem como seus/suas colegas e professores/as (SAMPAIO, 2004).

\section{Análise da experiência dos/as professores com o Estatuto da Criança e do Adolescente}

Abaixo estão listados os dados coletados na pesquisa, por meio de questionário, cujos percentuais foram separados de acordo com cada pergunta e analisados separadamente. Os dados coletados foram formatados em gráficos seguidos de análise.

Questão 1 - Qual seu nível de escolaridade?
( ) Graduação
( ) Pós-graduação-Nível

Gráfico 1 - Nível de escolaridade

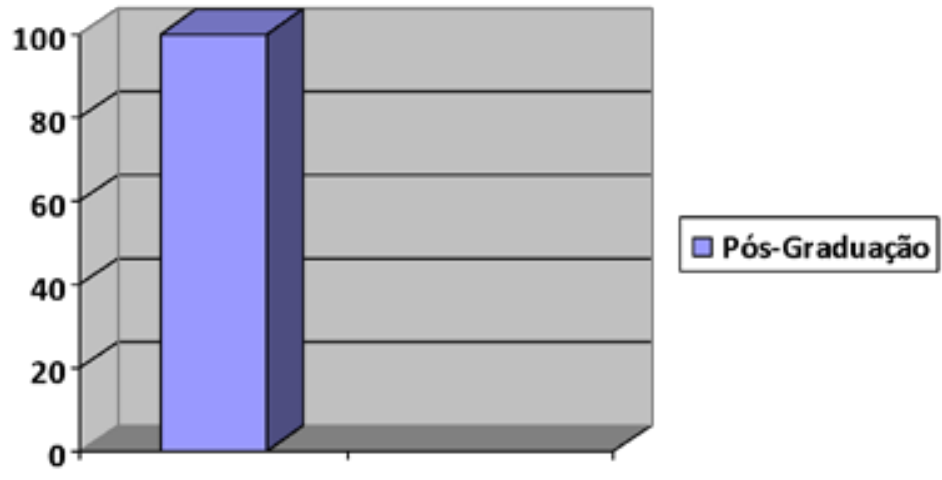

Fonte: Elaborado pelos autores.

Todos/as os/as professores/as que responderam ao questionário possuem pós-graduação, em nível de especialização ou mestrado. Este dado aponta para um bom nível de formação dos/as professores/as daquela escola. 
DESAFIOS DA EDUCAÇÃO NA GARANTIA DE DIREITOS:

PROFESSORES DO CURSO DE MAGISTÉRIO E SUA EXPERIÊNCIA COM O ESTATUTO DA CRIANÇA E DO ADOLESCENTE

Questão 2 - Em suas aulas para o curso de magistério é trabalhado o ECA? ( ) Sim - ( ) Não

Gráfico 2 - Utilização do ECA

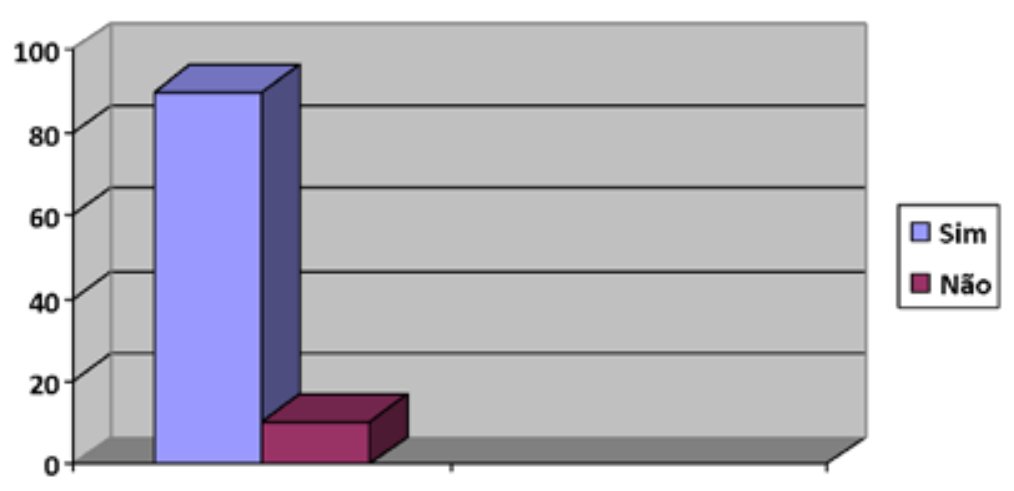

Fonte: Elaborado pelos autores.

Como pode ser observado no gráfico acima, $90 \%$ dos/as professores/as responderam que trabalham o ECA nas suas aulas, mesmo que seja de forma esporádica, sem constar no plano de ensino, ou apenas como referência ou citação. $O$ restante afirmou que o assunto não condiz com a disciplina lecionada. Infere-se que o ECA não se configura em conteúdo fundamental nas aulas dos/as professores/as do Colégio Sebastião Toledo dos Santos, pois, conforme as informações dos/as professores/as, esse conteúdo não consta nos planos de ensino, sendo abordado esporadicamente ou referenciado superficialmente.

Questão 3 - Já realizou algum curso na área dos direitos da criança e do/a adolescente?

( ) Sim - Qual:

( ) Não

Gráfico 3 - Participação em cursos na área dos direitos da criança e do/a adolescente

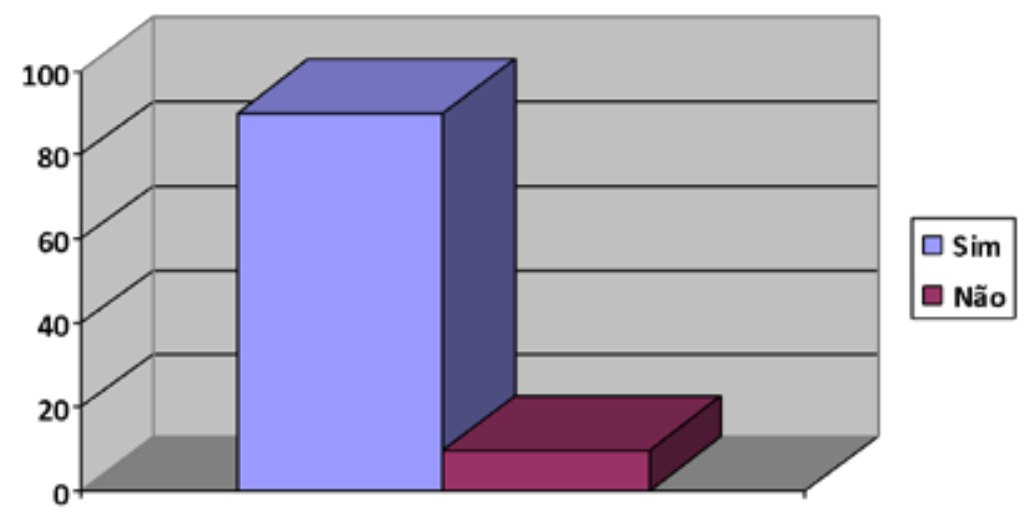

Fonte: Elaborado pelos autores. 
Neste caso, $90 \%$ dos/as professores/as já realizaram algum curso na área dos direitos das crianças e dos/as adolescentes, porém não citaram o nome do curso do qual participaram nem o nível de titulação. Apenas $10 \%$ dos/as professores/as nunca participaram de cursos nessa área. Infere-se que os tipos de cursos realizados pelos/as professores/as constituíram-se em cursos de curta duração (geralmente de 40 horas), que são oferecidos pelos órgãos governamentais - leia-se Secretarias de Educação ou Instituições -, Faculdades e Universidades da região. Cursos de especialização Latu Sensu ou Mestrado, por exemplo, que dariam maior fundamentação, não parecem fazer parte do rol de cursos realizados pelos/as profissionais da educação.

Questão 4 - Já identificou dentro da unidade escolar algum caso em que o direito da criança e do/a adolescente estava sendo violado? (abuso sexual, trabalho infantil, abandono, humilhação, bullying, violência doméstica ou física, etc.).

( ) Sim - Qual:

( ) Não

Gráfico 4 - Participação na identificação de violação dos direitos da criança e do/a adolescente

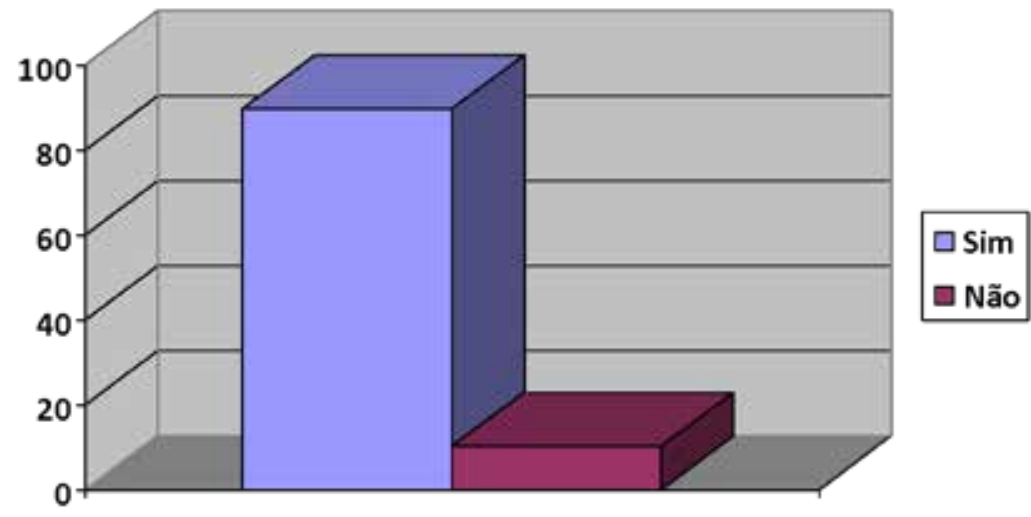

Fonte: Elaborado pelos autores.

Infelizmente, $90 \%$ dos/as professores/as que responderam ao questionário já identificaram algum caso em que o direito da criança e do/a adolescente foi violado. Os casos mais citados por eles/as foram violência doméstica, abandono, bullying ou humilhação. $O$ dado da pesquisa revela que a violação dos direitos da criança e do/a adolescente se faz presente no cotidiano escolar. Portanto, consideramos imperativo que o ECA esteja nos planos de ensino dos/ as professores/as, ou seja, que ele faça parte das disciplinas ministradas pelos/as professores/as e também do Plano Político Pedagógico (PPP) da Escola. Entendemos que, na escola, professores/as, supervisores/as, orientadores/as, psicólogos/as, diretores/as... devam conhecer o ECA e estar preparados/as para lidar com as situações como as descritas nesta pesquisa. 
DESAFIOS DA EDUCAÇÃO NA GARANTIA DE DIREITOS:

Questão 5 - Uma professora de ensino fundamental identificou marcas de violência física em uma aluna de 8 anos. Preocupada com a situação, chamou a mãe da criança na escola para conversar. A mãe da menina, ao ser interrogada, disse à professora que não se metesse naquele assunto para que não tivesse problemas futuros. Acrescentou, ainda, que tem um companheiro bem violento, o qual mandou dizer à professora que cuidasse apenas do seu trabalho. Nesse caso hipotético, como você reagiria sendo a professora?

Essa pergunta aberta foi colocada no questionário para que os/as professores/as pudessem expressar seus sentimentos e atitudes quanto ao caso hipotético relatado. Todos/as eles/as informaram que conversariam com a direção do colégio para encaminhar o caso aos órgãos responsáveis e que não se sentiriam intimidados com a fala da mãe quando ela informasse que tem um companheiro violento. Destaca-se que essa postura dos/as professores/as é extremamente importante, mesmo sendo um caso complexo no qual a própria imagem do/a profissional pode ficar exposta. Apesar do grau de dificuldade da abordagem, os/as professores/as demonstraram iniciativa para garantir o direito da criança, ou do/a adolescente, que estaria sendo violado no caso relatado hipoteticamente.

Em seu Artigo 101, o Estatuto da Criança e do Adolescente expõe que sempre que os direitos das crianças e dos adolescentes forem ameaçados ou violados por ação ou omissão da sociedade ou do Estado; por falta, omissão ou abuso dos pais ou responsáveis; ou em razão de sua conduta, as seguintes medidas de proteção poderão ser aplicadas:

I. encaminhamento aos pais ou responsável, mediante termo de responsabilidade;

II. orientação, apoio e acompanhamento temporários;

III. matrícula e frequência obrigatórias em estabelecimento oficial de ensino fundamental;

IV. inclusão em programa comunitário ou oficial de auxílio à família, à criança e ao adolescente;

V. requisição de tratamento médico, psicológico ou psiquiátrico, em regime hospitalar ou ambulatorial;

VI. inclusão em programa oficial ou comunitário de auxílio, orientação e tratamento a alcoólatras e toxicômanos;

VII. acolhimento institucional;

VIII. inclusão em programa de acolhimento familiar;

IX. colocação em família substituta. (ECA, 2012, p. 52-53).

Questão 6 - O Estatuto da Criança e do Adolescente (ECA - Lei $n^{\circ}$ 8.069/1990) considera criança a pessoa com idade até: ( ) Onze anos incompletos ( ) Doze anos incompletos ( ) Nove anos incompletos ( ) Dezoito anos incompletos 
Gráfico 5 - Conhecimento quanto à idade, considerada pelo ECA, que define a fase da criança

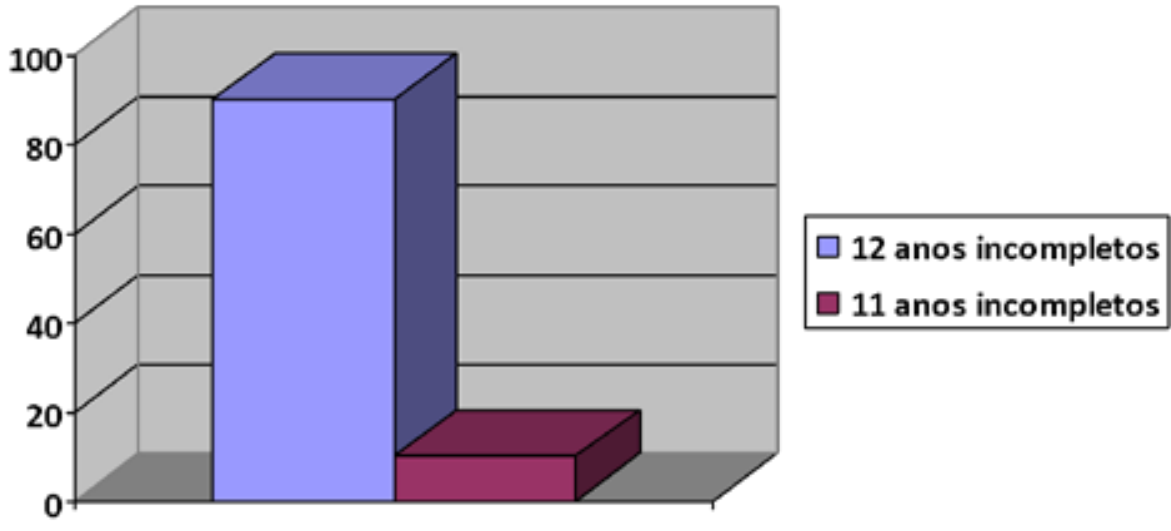

Fonte: Elaborado pelos autores.

Quanto à questão da idade, que o Estatuto da Criança e do Adolescente estabelece como sendo a que representa a fase da criança, $90 \%$ dos/as professores/as acertaram essa idade que é de 12 anos incompletos.

Questão 7 - 0 menor aprendiz pode trabalhar a partir de que idade? ( ) $14 \operatorname{anos}($ ) $16 \operatorname{anos}($ ) $10 \operatorname{anos}($ ) 18 anos

Gráfico 6 - Conhecimento quanto à idade do menor aprendiz

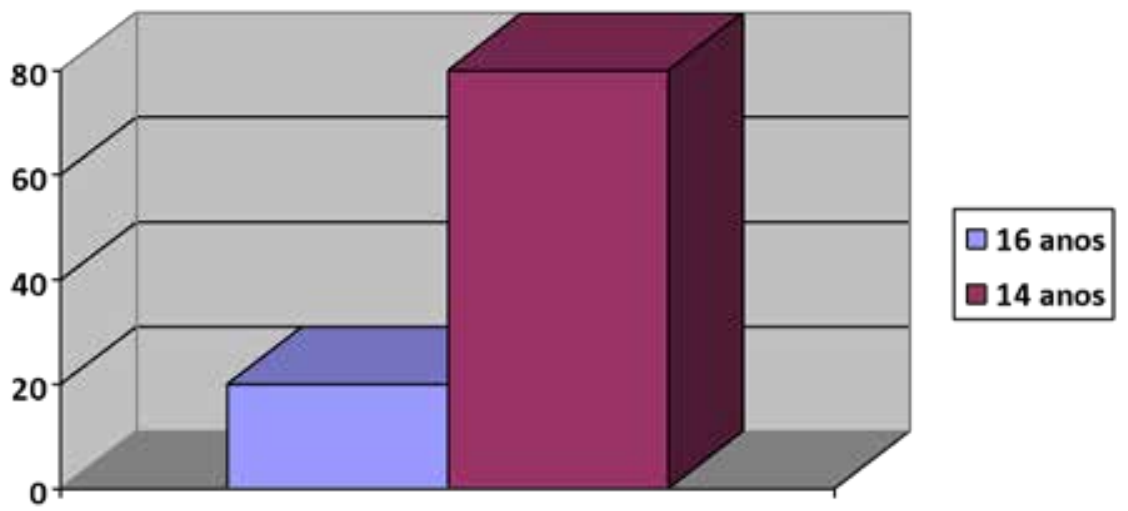

Fonte: Elaborado pelos autores.

A questão da idade mínima para o/a menor aprendiz é peculiar, pois o ECA considera menor aprendiz o indivíduo a partir dos 14 anos completos, porém é necessário que o menor esteja frequentando regularmente uma instituição de ensino e tenha um bom rendimento escolar. A pesquisa demonstrou que $80 \%$ dos/as professores/as sabem qual é a idade mínima para o menor 
DESAFIOS DA EDUCAÇÃO NA GARANTIA DE DIREITOS:

aprendiz trabalhar, e que $20 \%$ deles/as desconheciam essa informação. Esses $20 \%$ podem parecer pouco desconhecimento, mas entendemos que em um contexto de propaganda apontando para essa situação e cursos oferecidos na escola pelo Centro de Integração Empresa Escola - CIEE esse índice de desconhecimento pode ser considerado alto.

Libâneo (1990, p. 38), ao abordar a necessidade de democratização da Escola Pública, aponta para a responsabilidade do/a professor/a (o seu papel político na escola):

[...] é a consciência política dos professores que deve convergir para o trabalho que se faz dentro da escola com o numeroso contingente de alunos provenientes das camadas populares. $\mathrm{O}$ ensino é uma tarefa real e concreta que expressa compromisso social e político do professor, pois o domínio das diversas habilidades é requisito para a participação na vida profissional, na vida política e sindical e para enfrentar situações, problemas e desafios da vida prática. Um ensino de baixa qualidade empurra cada vez mais as crianças para a marginalização.

Portanto, podemos afirmar que o/a professor/a que tem clareza dos objetivos da educação e sua responsabilidade na formação intelectual e moral dos/as alunos/as, conseguirá, com muito mais eficácia, alcançar um aproveitamento escolar satisfatório das crianças.

Questão 8 - A criança e o/a adolescente/a têm direito à educação, sendo-Ihes assegurado:

( ) direito de contestar critérios avaliativos, podendo recorrer às instâncias escolares superiores

( ) direito de faltar $25 \%$ das aulas por motivo injustificado

( ) direito de repor as aulas perdidas por motivo de viagem

( ) direito de receber meio de locomoção gratuito até a escola

Gráfico 7 - Conhecimento quanto ao que é assegurado à criança e ao/à adolescente/a na educação

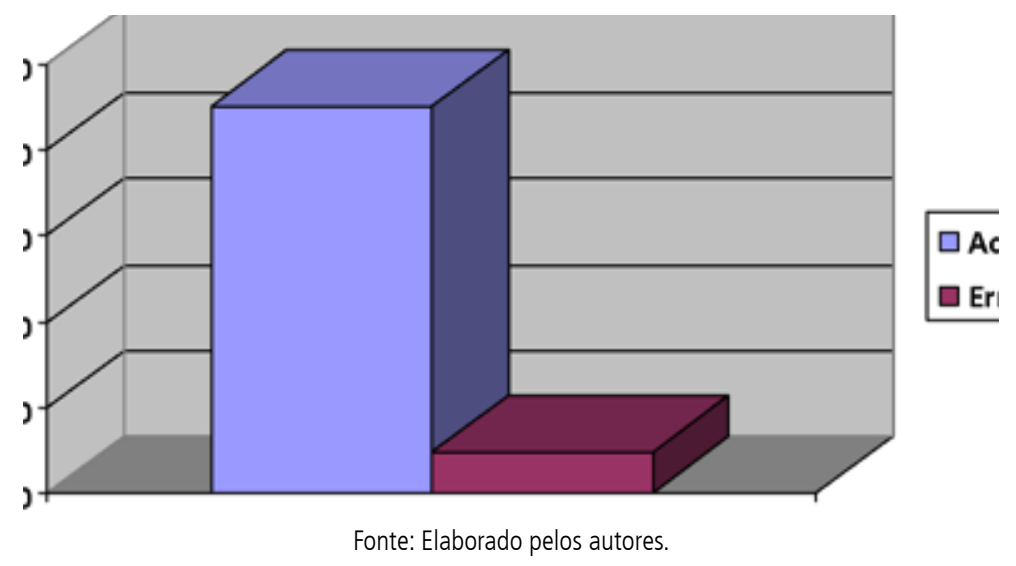


Essa questão conta com duas alternativas corretas e $90 \%$ dos/as professores/as acertaram pelo menos uma. As alternativas corretas seriam as duas primeiras, direito de contestar critérios avaliativos, podendo recorrer às instâncias escolares superiores, e direito de faltar $25 \%$ das aulas por motivo injustificado, sendo que no caso da segunda, mesmo que a quantidade de $25 \%$ de infrequência não influencie na possibilidade de reprovação do/a aluno/a, deve-se averiguar o motivo das constantes ausências, se elas ocorrem esporadicamente ou em dias consecutivos. O motivo da ausência, sendo consecutivo ou não, pode estar relacionado a alguma violação de direito. Assim, é fundamental que o/a professor/a conheça seus/suas alunos/as.

O professor deve conhecer as experiências sociais e culturais dos alunos: o meio em que vivem, as relações familiares, a educação familiar, suas motivações e expectativas em relação à escola e seu futuro na vida. Ainda, sabemos pouco sobre as condições de vida e o ambiente sociocultural que afetam a vida escolar das crianças pobres. Porém, essas desvantagens devem ser o ponto de partida para o trabalho docente, não somente confrontando as experiências de vida e conhecimentos sistematizados, mas incentivando o desejo de melhorar as condições de vida, mostrando a contribuição que a escola pode dar para superar essas desvantagens. (LIBÂNEO, 1990, p. 113-114).

Portanto, é imperativo a escola estar engajada na formação de educandos/as e educadores/as. Nesse processo, ela não pode "[...] alhear-se das condições sociais, culturais e econômicas de seus alunos, de suas famílias, de seus vizinhos." (FREIRE, 2011, p. 62).

Questão 9 - Os/as dirigentes de estabelecimentos de ensino fundamental comunicarão ao Conselho Tutelar os casos de: ( ) Indisciplina dentro da sala de aula ( ) Elevados níveis de repetência ( ) Faltas constantes injustificadas ( ) Agressividade e transtornos de humor

Gráfico 8 - Conhecimento quanto ao que os/as dirigentes de estabelecimentos de ensino fundamental devem comunicar ao Conselho Tutelar

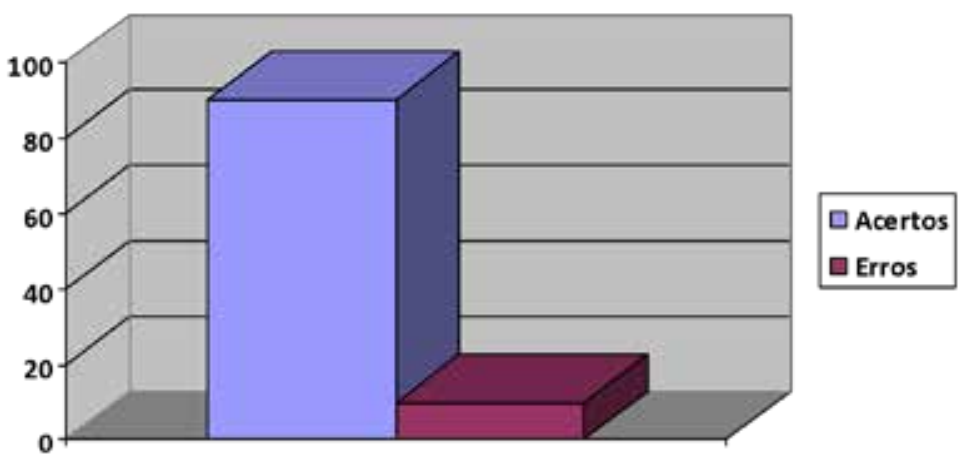

Fonte: Elaborado pelos autores. 
DESAFIOS DA EDUCAÇÃO NA GARANTIA DE DIREITOS:

PROFESSORES DO CURSO DE MAGISTÉRIO E SUA EXPERIÊNCIA COM O ESTATUTO DA CRIANÇA E DO ADOLESCENTE

Apesar da agressividade ou do transtorno de humor estarem potencialmente relacionados com algum fator de violação dos direitos da criança, o ECA não cita isso como motivo para encaminhamento, sendo que $10 \%$ dos/as professores/as responderam esta como sendo a alternativa correta. Nesse caso, a criança precisa de atendimento especializado, que seria, primeiramente, um/a orientador/a escolar e, posteriormente, um/a psicólogo/a ou psicopedagogo/a para identificar o problema e iniciar um acompanhamento com tratamento, visto que não compete ao conselho tutelar resolver esse tipo de situação. $\mathrm{O}$ que deve ser encaminhado para o conselho é a constante ausência do/a aluno/a por motivo injustificado. Nesse sentido, $90 \%$ dos/as professores/as assinalaram esta alternativa como correta. Conforme o Artigo 56 do ECA, é obrigatoriedade dos/as dirigentes de estabelecimentos de ensino fundamental comunicar ao Conselho Tutelar os seguintes casos: "[...] maus-tratos envolvendo seus/suas alunos/as; reiteração de faltas injustificadas e de evasão escolar, esgotados os recursos escolares e elevados índices de repetência." (ECA, 2012, p. 34). Ou seja, das quatro alternativas elencadas acima, duas são corretas, mas os/as professores/as acertaram apenas uma, dado que demonstra certo desconhecimento por parte deles/as de aspectos do ECA ligados diretamente à escola.

Questão 10 - Dentro da unidade escolar que você trabalha, o Estatuto da Criança e do Adolescente fica em lugar visível e disponível para consulta de todos/as?

( ) Sim - Em que local:

( ) Não

Infelizmente, dentro daquele ambiente escolar, o ECA não está disponível ou visível para consulta - $100 \%$ dos professores confirmaram isso. Essa questão é de suma importância, pois a falta de contato com o documento, tanto por parte dos/as professores/as quanto dos/as alunos/as, visitantes da escola e de toda a comunidade escolar pode gerar negligência em certos casos devido à falta de conhecimento dos direitos e garantias previstos no estatuto.

Dentro de uma visão geral, os gráficos apresentam valores satisfatórios com relação à pesquisa, demonstrando que todos/as os/as professores/as pesquisados/as possuem conhecimento sobre o ECA e o aplicam dentro da sua área de atuação. $O$ único ponto negativo a destacar é que dentro daquela unidade escolar o ECA não está disponível e visível aos/às professores/as, aos/às alunos/as ou visitantes e a toda a comunidade escolar. Todos/as os/as professores/as já presenciaram casos de negligência e deram encaminhamento do caso aos órgãos competentes. Além disso, todos/as os/as pesquisados/as possuem especialização, cursos e outras atividades relacionados ao tema estudado, o que os/as torna mais preparados/as na identificação de tais casos e na garantia dos direitos das crianças e dos/as adolescentes. 


\section{Conclusão}

Mediante a análise dos dados, foi possível identificar que, de modo geral, os/as professores/as do Colégio Sebastião Toledo dos Santos possuem conhecimento do ECA, mas não trabalham diretamente o conteúdo do estatuto na sua disciplina. Infelizmente, constatou-se que todos/as os/as professores/as pesquisados/as já identificaram casos de violência ou negligência na garantia dos direitos das crianças e dos/as adolescentes, mas felizmente denunciaram tais atos.

Apesar de observarmos diariamente os constantes problemas enfrentados na educação, em especial no Ensino Fundamental, que é de máxima importância na formação de um cidadão, acredita-se que quando esses/as profissionais são qualificados/as e bem preparados/as, eles/as podem fazer a diferença na vida de muitos outros cidadãos. O/a professor/a tem forte influência na vida de seus/suas alunos/as. Nesse sentido, quando está bem preparado/a para educar e preparar o/a aluno/a para a vida fora dos muros da escola, ele/a interfere não só na capacidade intelectual do/a aluno/a, mas também ajuda a construir um cidadão com valores, capaz de refletir, julgar, posicionar-se e agir frente aos problemas enfrentados na vida cotidiana.

Por fim, consideramos imperativo reconhecer o ECA como símbolo de defesa dos direitos fundamentais da criança, mas não apenas como uma legislação que estabelece direitos. É preciso romper com a precariedade da realidade vivida por milhares de crianças, em especial as das camadas populares, e vislumbrar uma perspectiva de futuro melhor para as crianças. Portanto, a utilização do ECA no cotidiano escolar configura-se em um dos caminhos possíveis para melhorar a vida das crianças e dos/as adolescentes. 
DESAFIOS DA EDUCAÇÃO NA GARANTIA DE DIREITOS:

PROFESSORES DO CURSO DE MAGISTÉRIO E SUA EXPERIÊNCIA COM O ESTATUTO DA CRIANÇA E DO ADOLESCENTE

\section{Referências}

AMIN, A. R. Curso de Direito da Criança e do Adolescente: Aspectos Teóricos e Práticos. Rio de Janeiro: Lumen Juris, 2010.

ARENDT, H. A condição humana. 10. ed. Rio de Janeiro: Forense, 2001.

BECKER, D. O que é a adolescência. São Paulo: Brasiliense, 1989.

BRASIL. Estatuto da criança e do adolescente: Lei federal n 8.069, de 13 de julho de 1990. Rio de Janeiro: Imprensa Oficial, 1990.

Estatuto da Criança e do Adolescente: Lei n 8.069/90, atualizada com a Lei n 12.010, de 2009; inclusa a Lei $n^{\circ}$ 12.594, de 2012. 3. ed. [S.I.]: Sinase, 2012.

CARVALHO, E. M. G. Educação infantil: percurso, dilemas e perspectivas. Ilhéus: Editus, 2003.

FREIRE, Paulo. Pedagogia da autonomia: saberes necessários à prática educativa. São Paulo: Paz e Terra, 2011.

KASSOUF, A. L. O que conhecemos sobre o trabalho infantil? Nova Economia, Belo Horizonte, v. 17, n. 2, p. $323-$ 350, ago. 2007.

LIBÂNEO, J. C. Democratização da Escola Pública: A Pedagogia Crítico-Social dos Conteúdos. Coleção Educar. São Paulo: Loyola, 1994.

MATHEUS, T. C. Quando a adolescência não depende da puberdade. Rev. latinoam. psicopatol. fundam., São Paulo, v. 11, n. 4, dec. 2008.

OLIVEIRA, M. K. de. Vygotsky: Aprendizado e desenvolvimento: um processo sócio-histórico. 4. ed. São Paulo: Scipione, 2005.

SAMPAIO, D. M. A pedagogia do ser: Educação dos sentimentos e dos valores humanos. Rio de Janeiro: Vozes, 2004. 